\title{
Design and optimization of power hubs for Brazilian off-shore oil production units
}

Vidoza, Jorge ; Andreasen, Jesper Graa; Haglind, Fredrik; Reis, Max ; Gallo, Waldyr

Published in:

Energy

Link to article, DOI:

10.1016/j.energy.2019.04.022

Publication date:

2019

Document Version

Peer reviewed version

Link back to DTU Orbit

Citation (APA):

Vidoza, J., Andreasen, J. G., Haglind, F., Reis, M., \& Gallo, W. (2019). Design and optimization of power hubs for Brazilian off-shore oil production units. Energy, 176, 656-666. https://doi.org/10.1016/j.energy.2019.04.022

\section{General rights}

Copyright and moral rights for the publications made accessible in the public portal are retained by the authors and/or other copyright owners and it is a condition of accessing publications that users recognise and abide by the legal requirements associated with these rights.

- Users may download and print one copy of any publication from the public portal for the purpose of private study or research.

- You may not further distribute the material or use it for any profit-making activity or commercial gain

- You may freely distribute the URL identifying the publication in the public portal 


\section{Accepted Manuscript}

Design and optimization of power hubs for Brazilian off-shore oil production units

Jorge Vidoza, Jesper Graa Andreasen, Fredrik Haglind, Max Reis, Waldyr Gallo

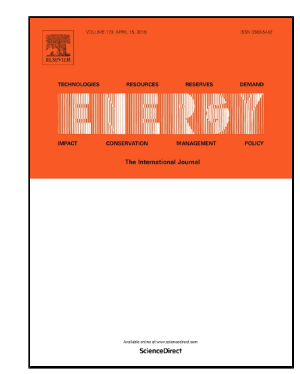

PII:

S0360-5442(19)30641-3

DOI:

10.1016/j.energy.2019.04.022

Reference:

EGY 15051

To appear in:

Energy

Received Date:

25 December 2018

Accepted Date:

04 April 2019

Please cite this article as: Jorge Vidoza, Jesper Graa Andreasen, Fredrik Haglind, Max Reis, Waldyr Gallo, Design and optimization of power hubs for Brazilian off-shore oil production units, Energy (2019), doi: 10.1016/j.energy.2019.04.022

This is a PDF file of an unedited manuscript that has been accepted for publication. As a service to our customers we are providing this early version of the manuscript. The manuscript will undergo copyediting, typesetting, and review of the resulting proof before it is published in its final form. Please note that during the production process errors may be discovered which could affect the content, and all legal disclaimers that apply to the journal pertain. 


\title{
Design and optimization of power hubs for Brazilian off-shore oil production units
}

\author{
Jorge Vidoza ${ }^{a}$, Jesper Graa Andreasen ${ }^{b}$, Fredrik Haglind $^{c}$, Max Reis $^{d}$, Waldyr Gallo $^{e}$ \\ ${ }^{a}$ Mechanical Engineering Institute, University of Campinas, Campinas, Brazil, jorgeavg@fem.unicamp.br \\ ${ }^{b}$ Department of Mechanical Engineering, Technical University of Denmark, Kongens Lyngby, Denmark, \\ jgan@mek.dtu.dk \\ ${ }^{c}$ Department of Mechanical Engineering, Technical University of Denmark, Kongens Lyngby, Denmark, \\ frh@mek.dtu.dk \\ ${ }^{d}$ Mechanical Engineering Institute, University of Campinas, Campinas, Brazil, \\ maxmauro@fem.unicamp.br \\ ${ }^{e}$ Mechanical Engineering Institute, University of Campinas, Campinas, Brazil, gallo@fem.unicamp.br
}

\begin{abstract}
:
A worldwide trend to reduce greenhouse gases emissions has encouraged researchers to study more efficient solutions in oil and gas Industry. Most offshore units are energized by equipment operating at low loads, increasing environmental impact. This work aims identifying optimal designs and layouts of a combined cycle floating power hub tailored for offshore oil production applications. The Brazilian pre-salt basin which forecast high fuel gas production is taken as a case study. A model was developed, integrating the design of the gas turbine, heat recovery units, steam turbine and condenser. Genetic algorithms were applied in two optimization approaches, single-objective and multi-objective. Three parameters were evaluated: equipment purchase cost, thermal efficiency and total weight. The results of the multi-objective optimization indicated that dual-pressure arrangements, featuring 3 gas turbines, 1 heat recovery steam generator and 1 steam cycle, could be an attractive design solution for power hubs. This arrangement has a low cost and weight, while the thermal efficiency is maintained at a reasonably high level (around $53.2 \%$ ). Moreover, results indicated that $\mathrm{CO} 2$ emissions may be reduced by $18.7 \%$ to $27.2 \%$ at design point and $19 \%$ for the power hub lifetime, when compared with the conventional energy supply scenario
\end{abstract}

Keywords:

Offshore Power Systems, Floating Power Plants, Multi-objective Optimization, Offshore Grids.

\section{Introduction}

In the past decades, environmental awareness supported changes in diverse economic sectors. Oil and gas activities in some regions are making efforts to adapt to these trends. With the depletion of traditional oil fields, offshore oil activities increased, particularly in deep-water oil fields. This is the case of Brazilian oil industry with oil activities focusing on the exploitation of the Pre-salt Basin. Several studies analysed opportunities to mitigate environmental impacts in the Brazilian case, [1,2] introduced $\mathrm{CO}_{2}$ emissions forecasts by performing an exergy analysis, and determining best opportunities for improvement in Brazilian off-shore units performance, other study trend for the Brazilian case proposed alternatives such as carbon capture [3] and the use of bottoming Organic Rankine Cycle (ORC) power systems [4,5].

Alternatives for the Norwegian case have been widely studied. Pierobon et al.. [6] performed several analyses for Rankine, Organic and Compressed Air bottoming cycles. Nguyen et al. [7] realized exergetic analyses also for bottoming cycles. These studies, along with the work presented by Nord et al. [8] compose an important state of art for the analysis of combined cycles (CC) in offshore facilities. Another approach of optimization was performed by Orlandini et al. [9] with the introduction of wind power links through offshore grids. In the context of offshore grids, Hetland et al. [10] introduced the concept of a floating power hub, which would centralize power supply for offshore oil production units, by means of a dedicated floating power plant. Each oil production unit usually contains an over dimensioned power module for electricity supply to be used for the whole lifetime of the production unit. In the floating power hub, individual power modules would be removed, and a centralized power plant would supply energy through submersible cables. Submarine 
pipelines would supply the fuel required by the power plant, by using the associated gas from the oil production.

In the study by Hetland et al. [10] the floating power hub concept was introduced along with preselected combined cycle components. In this case the component design was tailored to the Brazilian Pre-salt characteristics. Previous studies in the field of optimizing Combined Cycle components focused on the waste heat recovery unit (WHRU) design, either based on Once Through Boiler (OTB) designs or drum-type heat recovery steam generators (HRSGs). Manassaldi et al. [11,12] applied optimization procedures for onshore combined cycles. while Rovira et al. [13] considered off-design parameters for similar optimization objectives. Mehrgoo et al [14] compare performances among heat recovery steam generators of diverse pressure levels. Those authors analysed objectives separately, mainly because the onshore application in which either costs or efficiency are prioritized.

A literature review indicates that most studies regarding offshore power generation in oil platforms relate to already operating or built facilities, restricting the options to improve the plant performance. There are only a few studies concerning offshore power generation hubs based on associated gas extraction, and these are limited to the use of fixed commercial equipment sets $[10,15]$. Moreover, in previous works, gas turbines in CC optimizations for off-shore applications were generally considered as "black boxes". That is, gas turbines outputs were fixed due to an existing gas turbine in the offshore facility, restricting to a specific case. This is also the case for previous Brazilian studies [3,5], in which alternatives were based on the current FPSOs layout.

Kaviri et al [16] address the trade-off design for combined cycles by introducing a multi objective optimization including the gas turbine parameters. Nevertheless, the authors consider two main objectives, in which weight is not considered, as it analyses an onshore power plant. On the other hand, Riboldi et al [17] tackles a similar problem using GE LM2500 gas turbine and fixed layout scenarios. In the current paper, both parameters are integrated into the optimization process. Barbosa et al [18] explore different topping cycle technologies however a multi-objective optimization is not performed which could offer a wider range of results.

This paper analyses the performance of a floating power hub in order to reduce $\mathrm{CO}_{2}$ emissions and improve thermodynamic efficiency in a set of offshore oil production units. The objective is to identify optimal designs of a gas and steam turbine combined cycle for this application. Power hub arrangements could be interesting for oil production basins with several operative offshore units, the methodology could be used also for other off-shore applications for which similar trade-off analysis needs to be addressed.

Application restrictions need to be thoroughly studied for each case, some restriction examples could be: scarce fuel gas production, unavailability of infrastructure to sell surplus gas and operational aspects regarding heat demand. Benefits would also differ depending on the selected case, for example, in Brazil, benefits may rely in surplus gas opportunity cost, for the Norwegian case, less fuel consumption implies paying less carbon taxes, alternatively, when there is a link to shore benefits may be related to selling electricity to main grid.

For this article, Brazilian pre-salt basin is taken as a case study, power and heat demands are known and are based on expected production conditions [1]. It is assumed that surplus gas could be sold and delivered by submarine gas ducts, carbon taxes and link to shore scenarios are not considered. As mentioned, these boundary conditions and considerations could be modified depending of the application region. This study introduces the power hub design by exploring several component scenarios for maximum load conditions, for this purpose, optimization objectives tackles the tradeoff among combined cycle performance, weight and costs. It is well known that FPSOs suffer from diverse and drastic load changes along their lifetime, nevertheless, calculating other load conditions implies off-design performance, which is not part of the scope of this paper and it is analyzed in further studies.

The previous state-of-art revision allowed understanding the contribution of this paper to previous works. Studies on the literature are based on pre-established boundary conditions such as installed gas turbines or fixed size parameters. Studies for onshore combined cycle often do not consider 
weight as a main objective. This article addresses this gap by including the weight estimation in the combined cycle analysis and optimization objectives. In most cases for offshore applications oncethrough boiler is used as waste heat recovery unit. In this case, as a dedicated energy generation platform is considered, heat recovery steam generators of one and two pressure levels were analysed, this application was not found in literature.

Regarding the gas turbine approach, the present study integrates the gas turbine design in the optimization procedure, in order to increase the number of CC layout options, potentially leading to more cost-effective and efficient combined cycle designs, this approach was seen in some onshore combined cycle optimizations, as in aforementioned references $[16,19]$. This approach was not seen in previous studies regarding offshore combined cycle design. Commercial and tailored gas turbines comprehend the gas turbine selection, although constructing a customized gas turbine is unlikely, optimizing gas turbine allows understanding how design parameters, such as pressure ratio, turbine inlet temperature and isentropic efficiencies, behave over diverse objectives.

The article is structured as follows. Section 2 which presents a brief description of Brazilian FPSO units, followed by an optimization rationale and the thermodynamic, economic and physical model. Results obtained from the different approaches are detailed, compared and discussed in Section 3. Finally, section 4 contain the concluding remarks and recommendations for future works.

\section{Methodology}

\subsection{Floating Production Storage and Offloading (FPSO) installations}

Pre-salt "replicant FPSOs" are equipped with an energy module, consisting in four GE LM2500 gas turbines. Under the specific temperature, pressure and humidity conditions of the Brazilian pre-salt basin, the energy module total capacity reaches approximately $75 \mathrm{MW}$. Production forecasts indicate the possibility of obtaining an associated gas with a high percentage of $\mathrm{CO}_{2}$, along with the oil and water mixture. Two additional GE LM2000 turbines provide mechanical drive for a $\mathrm{CO}_{2}$ compression section.

A more specific overview of pre-salt FPSOs operation scenarios can be found in Gallo et al [1]. Combining both demands from the main power module and the $\mathrm{CO}_{2}$ compression module, total electric demand in a replicant pre-salt FPSO may reach up to $80 \mathrm{MW}$. The proposed floating power hub would cover the electricity demand for three FPSOs, aiming to concentrate supply in one power plant. Fuel gas being produced and treated in the vessels is sent to the power hub, and in turn, it sends electricity via submersible cables to each vessel. FPSOs needs a heat source to perform treatment and separation processes, in this sense, at least one cogeneration turbine must be left locally in each FPSO in order to fulfil such requirements, since other equipment burning gases directly would harm second thermodynamic law efficiency. The remaining three turbines could be hypothetically removed and the turbines used to energize $\mathrm{CO}_{2}$ compressors could be replaced by electrical drives. The total demand of three FPSOs would sum up to $240 \mathrm{MW}$ and considering that at least $25 \mathrm{MW}$ must be left in each vessel (and adding a reserve margin), it is estimated that the minimum installed capacity to be supplied by the power hub is $165 \mathrm{MW}$.

For this study, reduction in fuel consumption and $\mathrm{CO}_{2}$ emissions are considered in one-year time frame, operating at peak demand. A business-as-usual scenario in which the three FPSOs remain separated, estimated $\mathrm{CO}_{2}$ emissions are approximately $455.686 \mathrm{t} /$ year for each FPSO, a single gas turbine left for cogeneration implies $127.892 \mathrm{t}$ /year. BAU scenario is the base for comparing benefits of the power hub arrangement.

\subsection{Optimization method}

The overall calculation integrates several thermodynamic, sizing and economic methods, all equipment follows the same reasoning: first determine thermodynamic parameters, followed by a dimensional analysis and finishing with cost estimations. This framework is integrated in an 
optimization procedure, which is performed using Genetic algorithms (GA) because their versatility and capacity to deal with non-smooth objective functions. A fitness function and a constraint vector compose the GA calculation, which runs in MATLAB software [20]. A standard GA runs all optimization cases, optimization parameters are set as follows: crossover fraction 0.8 , migration fraction 0.2 , population size 200 and 4800 generations. The algorithm converges in approximately 4800 - 5000 seconds, running in a $3.40 \mathrm{GHz}$ Intel Core i7-3770 CPU. Areas and pressure calculations take longer, due to the large iteration processes to avoid unacceptable pressure levels.

Two approaches were considered in this study, single-objective and multi-objective optimization. In onshore power plants, usually space and weight requirements are omitted. However, in an offshore facility, space and weight may influence the overall capital costs. Furthermore, as the main objective of a floating power hub is to improve efficiency in FPSOs energy supply and thus, reduce $\mathrm{CO}_{2}$ emissions, the design procedure becomes a trade-off among costs, size and efficiency. In order to assess such trade-offs, three objectives were established, see Eq. (1) to (3): 1 - Minimizing costs, which will be evaluated as the total purchasing equipment costs for the power plant: the sum of the individual costs of gas turbines, steam turbines, HRSGs, pumps and condensers (PEC). 2 Minimizing the total mass, resulting from the sum of the individual weights of the power plant aforementioned equipment $\left(\mathrm{M}_{\mathrm{cc}}\right)$. 3 - Maximizing thermal efficiency, having as consequence reduction of fuel consumption and $\mathrm{CO} 2$ emissions $\left(\eta_{\mathrm{CC}}\right)$.

$$
\begin{aligned}
\mathrm{f}_{1}(\overline{\mathrm{X}}) & =[\mathrm{PEC}] \\
\mathrm{f}_{2}(\overline{\mathrm{X}}) & =\left[\mathrm{M}_{\mathrm{cc}}\right] \\
\mathrm{f}_{3}(\overline{\mathrm{X}}) & =\left[\eta_{\mathrm{cc}}\right]
\end{aligned}
$$

The three objectives were assessed separately (single-objective optimization) and as a threedimensional objective for a trade-off analysis (multi-objective optimization). As seen in Equation 1, a function containing thermodynamic, dimensional and economic modelling for the combined cycle is applied to evaluate the established objectives. $\overline{\mathrm{X}}$ is a vector of decision variables, each input of this vector corresponds to design parameters of each considered component. The decision variable vector is composed by 2 or 3 integer variables, depending on the GT case, 5 gas turbine design variables (isentropic efficiencies, maximum temperature, pressure ratio and nominal rating), $8 \mathrm{HRSG}$ and steam cycle variables (pressures, pinch points, live steam temperature, height and width of the HRSG) and 7 dimensional variables (number of tubes, diameters and fin dimensions).

A series of combined cycle blocks compose the floating power hub. A combined cycle block can have diverse arrangements, one to four gas turbines are combined with a single Rankine cycle. In the same way, one waste heat recovery unit can be shared by two or four gas turbines, in order to reduce space and weight requirements. The proposed model accounts with integer variables to find an optimum layout. Depending on the optimization approach, integer and binary variables represent the size (GTI) and quantity (NTR) of gas turbines, and whether if each is coupled to a HRSG or one HRSG is shared by the GT group (HXI), as displayed in Fig. 1. The introduction of such variables to the model makes it necessary to establish a Mixed Integer Non-Linear Programming (MINLP), in order to select among these discrete values. This implementation is particularly useful when modelling the options for the gas turbine technologies.

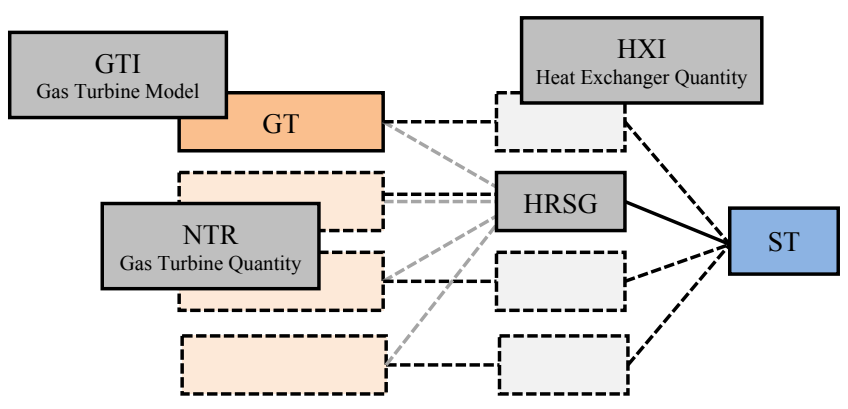




\section{Fig. 1. Integer variables which define the combined cycle layout}

The model starts establishing design parameters for the GT, which derive in a specific set of characteristics of the exhaust gases. An initial pinch point temperature value for the HRSG along with GT exhaust gases characteristics are main inputs to determine heats and duties in each HRSG section, namely: economizer, evaporator and super heater. When the mass flow rates and enthalpies are determined, the steam turbine and condenser thermodynamic parameters are calculated. In this stage, the thermodynamic equilibrium in each component is verified, to avoid temperature crosses and fluid phase inconsistencies. Solutions not meeting thermodynamic equilibrium in all nodes are discarded.

If the candidate solution is consistent, then the physical properties of the components can be evaluated. The specific design for the HRSG is carried out and pressure drops are determined. If total pressure drops on the exhaust gases side exceed 0.1 bar the solution is also discarded. Physical properties such as weight and size are also calculated for the gas turbine and condenser. The calculated transfer areas, duties, thermodynamic and physical properties are main inputs for the cost estimation of the combined cycle equipment. Solutions are evaluated in an iterative process until reach a minimum or maximum value. Fig. 2 depicts the optimization cases and processes.

Gas Turbine Selection and Inputs CC Temperature profile, dimensional analysis and pressure drop check Results vector

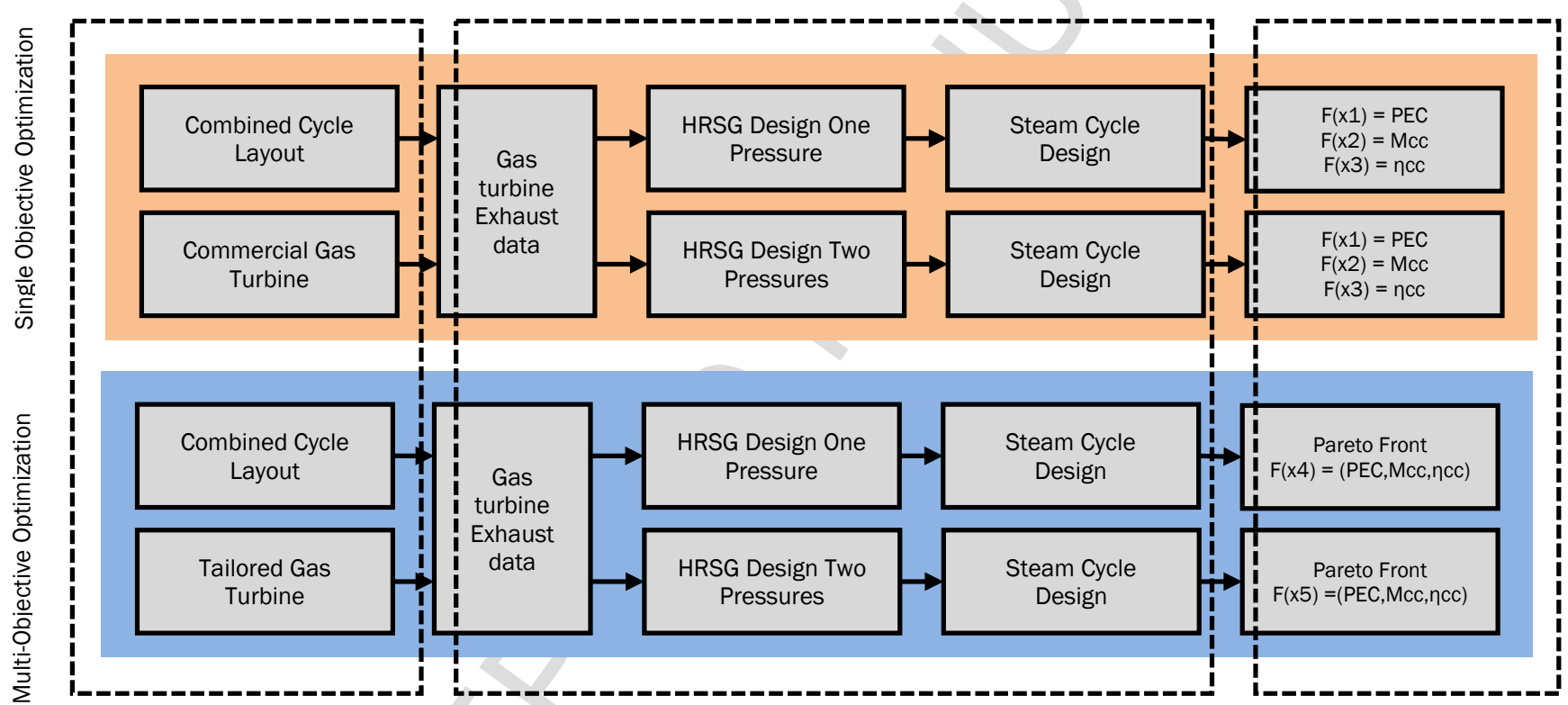

Fig. 2. Optitmization cases and procedure overview

\subsection{Gas turbines}

\subsubsection{Discrete analysis - commercial gas turbines}

In order to span a considerable range of possibilities, four gas turbines were selected: (i) GE LM2500, (ii) SGT-700, (iii) GE LM6000, and (iv) SGT-800. GE LM2500 and SGT-700 are commonly used gas turbines for offshore applications like FPSO units and Floating Liquefied Natural Gas (FLNG) ships. Particularly LM2500 has been widely studied and it is installed in two of the currently operating offshore combined cycles in Norwegian platforms, Snorre-B and Oseberg. From a scale economy and efficiency point of view, larger turbines closer to what is actually used in on-shore applications are also considered: GE LM6000 is used for larger scale combined cycles and for cruise and ship propulsion. SGT-800, which has the largest power rating among the studied turbines, is mostly used in simple/combined cycle and cogeneration applications. The algorithm selects one of the four gas 
turbines to compose the combined cycle. Parameters such as temperatures and pressure ratios are inherent of each gas turbine. Gas turbine performances are obtained using the commercial software Thermoflex ${ }^{\circledR}[21]$.

\subsubsection{Continuous analysis - gas turbine parameter design}

For the multi-objective optimization approach, the gas turbine parameters are modeled from the governing thermodynamic equations. The gas turbine is divided into four components: compressor, combustor, compressor turbine and power turbine, as seen in the simplified schemes in Fig. 3 and Fig. 4. In this case, the parameters defining the gas turbine design are the following: pressure ratios, turbine inlet temperature and compressor and turbine isentropic efficiencies. This allows the optimization search among continuous and smooth variables. Toffolo and Lazzaretto [19] applied multi-objective optimization for a single-shaft gas turbine. For this study, a similar optimization structure was proposed, considering a double shaft gas turbine. For this arrangement, there must be compatibility between the work delivered by the compressor turbine and the compressor power requirements. Additionally, there must be flow compatibility all along the expansion processes. Thermodynamic considerations and main design equations implemented follow Saravanamuttoo et al.. [22].

In order to estimate the gas turbine weight a correlation was used, based on the methodology applied in Ref. [23]. A set of 9 commercial gas turbines and their weights were considered to obtain the correlation which depends on the turbine capacity in MW. Even though correlation does not reflect exact weight because of the particularities of each commercial design, it reflects an acceptable estimation for the overall cc mass estimation $\left(\mathrm{R}^{2}=0,77\right)$.

\subsection{Steam Cycle}

\subsubsection{Single pressure heat recovery steam generator}

In case of one pressure level the HRSG is divided in three main sections: economizer, evaporator and super-heater. The gas turbine arrangement established by the integer variables determines the exhaust gases mass flow rate into each HRSG. In Equation 4, NTR can take values from 1 to 4. The heat exchanger index is a binary variable used to determine the quantity of heat exchangers. If this index equals zero, $\mathrm{HXI}=1$, all gas turbines share a single HRGS. If the index is equal to one, $\mathrm{HXI}=\mathrm{NTR}$, each gas turbine is coupled to a separate HRSG:

$$
\mathrm{m}_{\text {gas,total }}=\mathrm{m}_{\text {gas }} \mathrm{NTR} / \mathrm{HXI}
$$

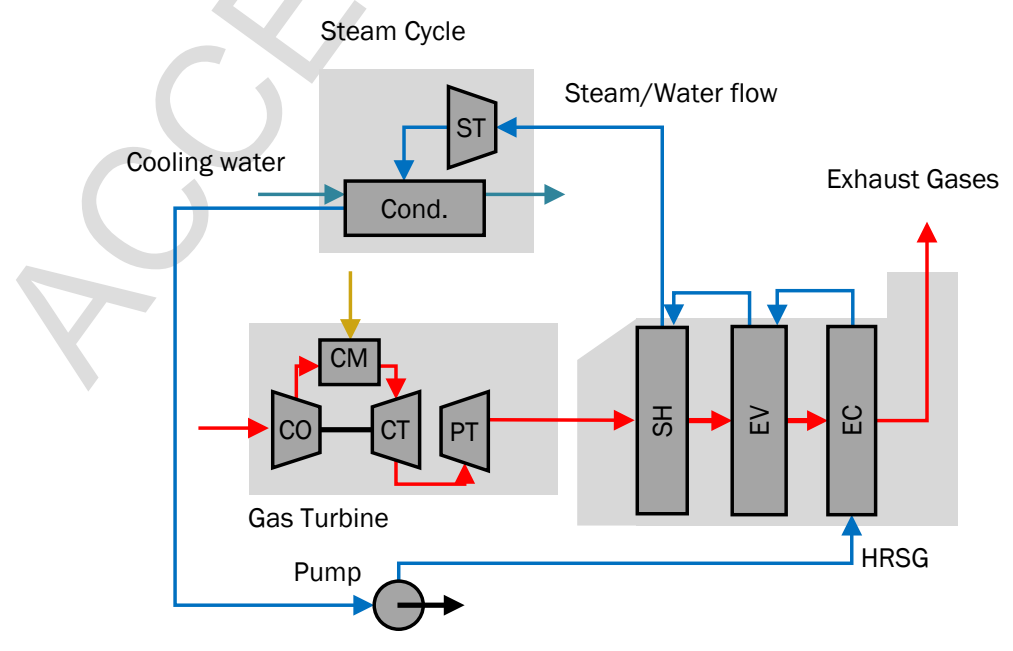

Fig. 3. Simplified one pressure level layout 
The mass flow rate of water is found by using the pinch point temperature difference. Fig. 3 shows a simplified system layout, with main flows and components. The steam cycle performance corresponding to one pressure level is determined by the temperature of steam exiting the HRSG, as seen in Equations 5 and 6, known as the live steam temperature, condenser pressure and steam turbine isentropic efficiency. Ambient conditions also affect the steam cycle, as the condensation pressure is limited by the ambient temperature. The condenser is assumed to be of shell-tube type, in which the cooling fluid would be treated seawater, and the operational pressure would be a decision variable set by the optimization procedure.

$$
\begin{gathered}
P P=T_{2 \_ \text {ev_gas }}-T_{\text {sat }} \rightarrow T_{2 \_ \text {ev_gas }}=P P+T_{\text {sat }} \\
Q_{\text {ev_sh }}=\dot{m}_{\mathrm{g}} C p_{g}\left(T_{\text {exh_GT }}-T_{2 \_ \text {ev_gas }}\right)=\dot{\mathrm{m}}_{\mathrm{w}} \Delta \mathrm{h}
\end{gathered}
$$

\subsubsection{Dual pressure heat recovery steam generator}

The dual pressure arrangement is based on a typical configuration studied by Manassaldi [11]. In this case there are two economizers, super-heaters and evaporators, thus doubling the number of sections of the previous arrangement, and therefore adding more complexity to the system. The order and disposition of these sections is as seen in Fig. 4. At the entrance, the low-pressure economizer handles one stream of water flow, which then divides at its outlet. A part of this main stream is sent to a pump to follow the high-pressure sequence to the evaporator and super-heater, the remaining mass flow rate is directed to the low-pressure sections.

This system has a low-pressure pump, handling the complete stream of water flow rate, and a highpressure pump which increases the pressure of the high-pressure water mass flow. The calculations for estimating mass flow rates are similar to the single-pressure arrangement. This case considers two different streams, a low-pressure and a high-pressure stream. The mass flow rates are calculated based on assumed pinch point values in the low-pressure and high-pressure sections, and the energy balances of each boiler section. Equations 7 to 10 shows the calculation procedure.

In this case, there are two steam turbines, one for each pressure level. The high-pressure steam turbine receives the live steam from the HRSG and expands down to the low-pressure level. At this point the high-pressure stream is mixed with the stream coming from the low-pressure super-heater, to enter the second turbine, and finally expanding to the condenser operational pressure. The power output of the steam cycle will be the sum of both high and low-pressure steam turbines.

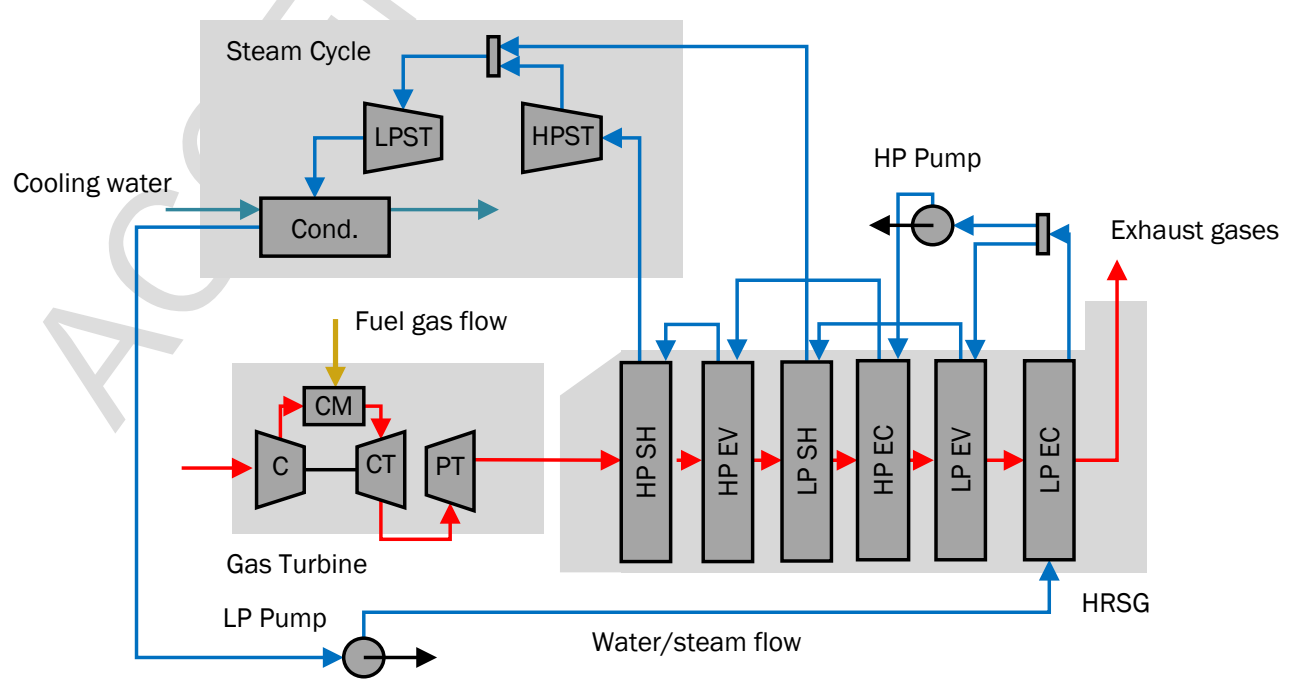

Fig. 4 Two pressure HRSG simplified layout 


$$
\begin{gathered}
{\left[\dot{\mathrm{Q}}_{\mathrm{ec}, \mathrm{ev}, \mathrm{sh}}=\dot{\mathrm{m}}_{\mathrm{gas}} \mathrm{C}_{\mathrm{p}}\left(\mathrm{T}_{1}-\mathrm{T}_{2}\right)=\dot{\mathrm{m}}_{\mathrm{w}}\left(\mathrm{h}_{2}-\mathrm{h}_{1}\right)\right]_{\mathrm{LP}, \mathrm{HP}}} \\
\dot{\mathrm{W}}_{\mathrm{LPST}}=\dot{\mathrm{m}}_{\mathrm{W}_{-} \mathrm{HP}}\left(\mathrm{h}_{2 \mathrm{shH}}-\mathrm{h}_{2 \mathrm{shL}}\right) \\
\dot{\mathrm{W}}_{\mathrm{HPST}}=\left(\dot{\mathrm{m}}_{\mathrm{W}_{-} \mathrm{HP}}-\dot{\mathrm{m}}_{\mathrm{W}_{-} \mathrm{LP}}\right)\left(\mathrm{h}_{2 \mathrm{shL}}-\mathrm{h}_{\mathrm{cond}}\right) \\
\dot{\mathrm{W}}_{\mathrm{ST}}=\dot{\mathrm{W}}_{\mathrm{LPST}}+\dot{\mathrm{W}}_{\mathrm{HPST}}
\end{gathered}
$$

\subsubsection{Heat recovery steam generator dimensioning}

The dimensioning methodology follows the same procedure whether the HRSG has a single or dual pressure arrangement. A bundle of finned tubes disposed vertically conforms each section. Exhaust gases flow horizontally through the tube bundle and enclosure. Each section; economizer, evaporator and super heater, for high and low pressure are calculated separately. Dimensional values cannot be assumed arbitrarily, as there is a strict trade-off among size, heat transfer and costs. The overall heat transfer coefficient method is applied to determine heat transfer areas in each HRSG section. An inline arrangement with plain fins is considered to calculate the heat transfer coefficient, adapting the methodology applied by Dumont [24].

The method is based on the heat transfer area outside the tubes. Calculation of the heat transfer coefficient for the exhaust gases depends on an average outside heat transfer coefficient and on the dimensional inputs, which are used to calculate the Colburn Factor, and a term including the efficiency of the heat transfer through the fins. The heat transfer coefficient and friction factors for fully developed turbulent flow inside the tubes were determined according to the correlations by Gnielinski [25].

The obtained heat transfer area through the dimensional set al.so results in specific pressure drops, which are evaluated in each HRSG section. A high backpressure for the gas turbine is detrimental for its performance. Likewise, excessive pressure drops in the water/steam affects the steam cycle power output. Pressure drop in exhaust gases side is determined by a set of non-dimensional values detailed in Refs. [24] and [26]. Pressure drops in the Steam/Water side are calculated as in [14].

\subsubsection{Weight estimation of steam cycle components}

Dimensional characteristics obtained for each heat transfer section are the base for estimating piping material weight, which accounts for an important share of the total HRSG and condenser weight. For the condenser case it was estimated that the total weight is governed by the piping installed in it, by establishing a fixed overall heat transfer coefficient. Nevertheless, for the HRSG, additional components have an important impact on its total weight. When using the weight correlation for the HRSG proposed by Rivera-Alvarez [23], weight results are, in average, larger than those obtained by calculating the tubing weight; the main reason being that the correlation by Rivera-Alvarez [23] includes a rough estimation of other components, such as drums and casing. Therefore, the correlation by Rivera-Alvarez [23] was applied for the HRSG in the optimization model of this work. The steam turbine and generator weight were calculated using the methodology followed by Rivera-Alvarez [23] and Haug [27], assuming that the steam turbine weight is proportional to the steam mass flow rate passing through the turbine.

\subsection{Economic evaluation}

The implementation of a power hub entails a complex economical evaluation, as it gathers diverse generation technologies along with various operational alternatives. In this study, the economical evaluation is limited to the equipment costs of the combined cycle power plant (PEC), as they are expected to be the most important share of the total power hub capital costs. Equipment costs are strongly dependent on the combined cycle configuration and gas turbine rating. Updated gas turbine costs for commercial devices were obtained using Thermoflex ${ }^{\circledR}$, while cost estimations for the gas 
turbine dimensioning approach was made using the continuous correlation described in Ref. [28]. Costs for steam turbine, HRSG, pumps, and electric generator were calculated as stated in Frangopoulos [29], and updated by Carapellucci and Giordano [30] and Roosen et al.. [31]. The condenser cost was estimated using the approach suggested by Shah [32]. All correlations result values in USD corresponding to year 2018.

As the power hub is divided in combined cycle blocks, it is expected that the quantity of blocks installed have a significant impact on the purchasing equipment costs. Quantity indexes for the combined cycle components and blocks are similar as those used in the total weight calculation.

\section{Results and discussion}

\subsection{Model validation}

A validation was carried out to simulate the heat recovery steam generator thermodynamic outputs. Manassaldi et al [12] validated the optimization procedure by comparing other optimized layouts in the literature with similar boundary conditions. In this study, the validation was executed by verifying the performance of a heat recovery steam generator, resulting from the optimization procedure. The optimization results in a vector with a set of dimensional, thermodynamic and integer variables. The gas turbine exhaust gases parameters were fixed at design point, and the downstream equipment. heat recovery steam generator, steam turbine and condenser, were reconstructed in Thermoflex [21], by setting the dimensional and operational values obtained in the optimization procedure, namely, pinch points, piping dimensions and layouts. The case of efficiency optimization for double pressure is taken as reference to validate the preliminary outputs. Resulting steam turbine performance parameters and design pressures from Thermoflex were compared with values of the proposed model. In practice, this validation allows verifying if the proposed heat recovery unit configuration is able to produce the estimated power from the steam cycle, considering a nominal gas turbine output.

The validation results feature a temperature profile from the heat recovery steam generator components and several output parameters regarding power generation; a comparison of these results between the model and Thermoflex is shown in Table 1. Deviations in the temperature nodes are below $1.8 \%$. As may be seen in Table 1 there are no deviations larger than $6,5 \%$, indicating that model for steam cycle design developed in this work provides reasonable results for the established objectives.

Table 1. Results of the validation of the steam cycle design model

\begin{tabular}{lrrr}
\hline Parameter & Model & Thermoflex & $\begin{array}{r}\text { Deviation } \\
\text { (\%) }\end{array}$ \\
\hline Steam turbine power output (MW) & 11.03 & 10.96 & 0.68 \\
Mass flow rate HP (kg/s) & 8.25 & 8.52 & -3.21 \\
Mass flow rate LP (kg/s) & 2.08 & 2.04 & 2.21 \\
High pressure (bar) & 79.91 & 78.67 & 1.55 \\
Low pressure (bar) & 10.60 & 9.91 & 6.51 \\
Turbine inlet temperature (K) & 749.32 & 742.40 & 0.92 \\
\hline
\end{tabular}

\subsubsection{Single-objective Optimization}

For the following results, the nomenclature used for representing the layout of the combined cycle blocks is simplified as follows: the number of gas turbines, followed by the number of heat recovery steam generators, and finally the number of steam turbines. Therefore, a 2(1)x1 block configuration, has two gas turbines with a shared HRSG and one steam turbine.

This optimization procedure allows analysing extreme points of the variable solution set. Table 2 and Table 3 highlight the most important parameters of the single-objective optimization procedure. There 
are similarities of the obtained arrangements for both pressure levels. The number of gas turbines and blocks are similar in both cases. Results in one objective optimization tend to reduce blocks in 1(1)x 1 arrangements. This allows improving the heat exchange by increasing the heat transfer area in HRSGs delivering steam for a single steam turbine, however, such layout results in a considerable increase in weight.

Optimized dual-pressure arrangements result in more compact combined cycles and smaller HRSGs when compared with single-pressure configurations. These results are mainly because achieving maximum efficiencies requires greater heat transfer areas when dealing with one pressure configurations. Likewise, weight minimization is obtained to the detriment of the heat transfer area. The results provide a less efficient system for the dual-pressure configuration, including one shared HRSG, and having the same model and quantity of gas turbines as the single-pressure case with three separated HRSGs.

Minimizing equipment costs results in the lowest performance levels. Besides the lowest heat transfer areas for the whole system, minimizing costs also follows the lowest operating pressures in both the single and dual-pressure configurations. Reduced areas and low pressures decrease size of equipment, reducing its efficiency but not necessarily diminishing total weight; the main reason being the selection of gas turbine SGT-800 which holds the lowest cost per MW and the largest weight.

Table 2. Single-objective single pressure optimization results

\begin{tabular}{lrrr}
\hline Optimization case & Efficiency $\left(\boldsymbol{\eta}_{\mathbf{c c}}\right)$ & Costs (PEC) & Weight $\left(\mathbf{M}_{\mathbf{c c}}\right)$ \\
\hline Combined Cycle Design & & & \\
GT Model & LM6000 PA & SGT-800-50 & LM2500+PV \\
CC Layout & $1(1) \times 1$ & $1(1) \times 1$ & $3(3) \times 1$ \\
Groups & 4 & 3 & 2 \\
HTA (m $\left.{ }^{2}\right)$ & 43182 & 19340 & 9145 \\
$\mathrm{~W}_{\text {ST }}(\mathrm{MW})$ & 13.60 & 11.67 & 28.09 \\
\hline Objective Values & & & \\
$\eta_{\mathrm{CC}}(\%)$ & $\mathbf{5 3 . 2 8}$ & 46.22 & 51.80 \\
PEC (MMUSD) & 122.02 & $\mathbf{8 0 . 6 7}$ & 130.00 \\
$\mathrm{M}_{\text {total }}(\mathrm{t})$ & 2588 & 1895 & $\mathbf{1 2 6 2}$ \\
\hline
\end{tabular}

In all cases, there are important reductions in fuel consumption due to the application of combined cycles. Diminishing fuel consumption is directly related to reducing $\mathrm{CO}_{2}$ emissions., results obtained in this paper suggest that it would be possible to reduce business-as-usual emissions in a range between $18.7 \%$ and $27.2 \%$ at peak demand for the dual-pressure steam cycle configuration by applying the weight minimization and efficiency maximization optimizations, respectively.

Table 3. Single-objective dual-pressure optimization results

\begin{tabular}{lrrr}
\hline Objective & Efficiency $\left.\boldsymbol{\eta}_{\mathbf{c c}}\right)$ & Costs (PEC) & Weight $\left(\mathbf{M}_{\mathbf{c c}}\right)$ \\
\hline Combined Cycle Design & & & \\
GT Model & LM2500+PV & SGT-800-50 & LM2500+PV \\
CC Layout & $1(1) \times 1$ & $1(1) \times 1$ & $3(1) \times 1$ \\
Groups & 5 & 3 & 2 \\
HTA $\left(\mathrm{m}^{2}\right)$ & 26297 & 18488 & 19306 \\
$\mathrm{~W}_{\text {ST }}(\mathrm{MW})$ & 11.28 & 14.62 & 22.90 \\
\hline Objective Values & & & \\
$\eta_{\text {CC }}(\%)$ & $\mathbf{5 4 . 6 4}$ & 48.67 & 49.23 \\
PEC $($ MMUSD) & 123.00 & $\mathbf{9 0 . 7 0}$ & 133.00 \\
$\mathrm{M}_{\text {total }}(\mathrm{t})$ & 1536 & 1540 & $\mathbf{8 5 8}$ \\
\hline
\end{tabular}


In order to detail the combined cycle dimensions on the power hub, a series of scaled layout views were created, based on the obtained dimensions. In this case, the dimensions of the gas turbines are known. All figures are in the same scale to compare all optimization cases on the same basis. Fig. 5 shows the three optimization cases for the single pressure layouts, whilst Fig. 6 represents the double pressure layouts. It is possible to observe that the layout is the main driver into determining the space required; the steam turbine itself represent a relatively small volume when compared to the remaining components.

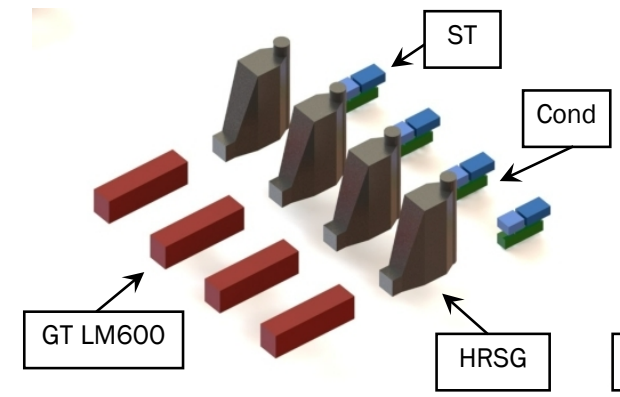

(a)

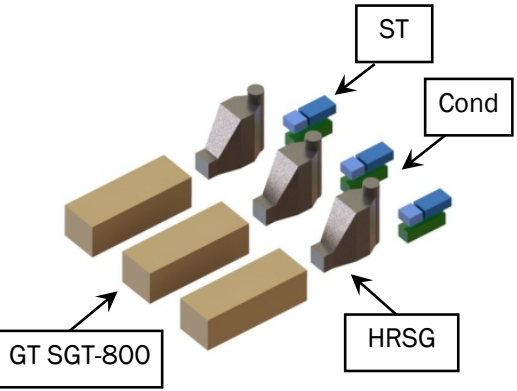

(b)

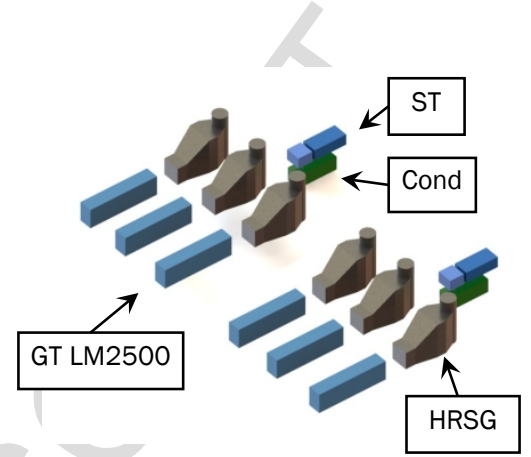

(c)

Fig. 5 Single Pressure layouts approximate volumetric representations: (a) Thermodynamic Efficiency $\left(\eta_{c c}\right)$, (b) Equipment costs $(P E C)$, (c) Weight $\left(M_{c c}\right)$

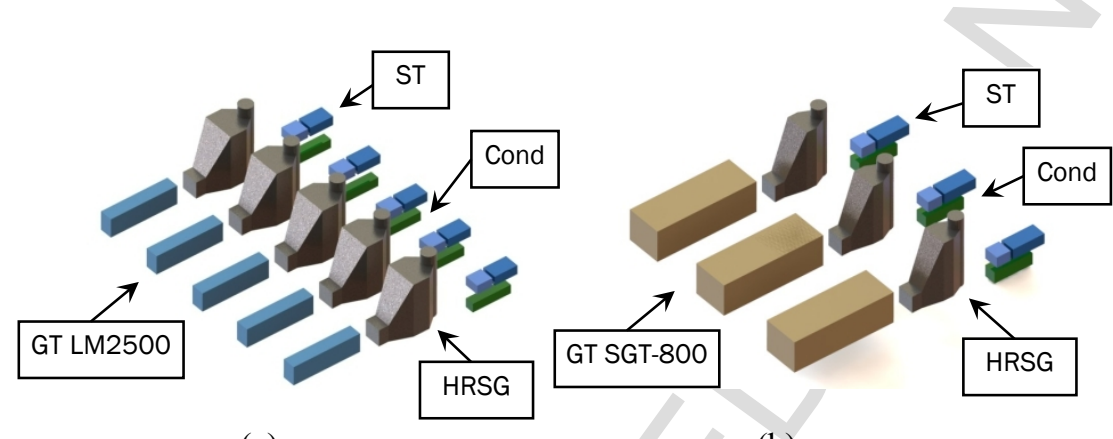

(a)

(b)

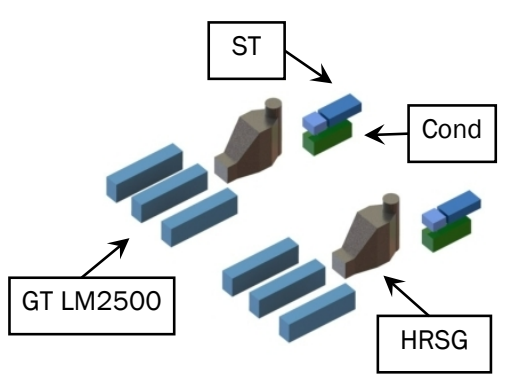

(c)

Fig. 6 Double Pressure layouts approximate volumetric representations: (a) Thermodynamic Efficiency $\left(\eta_{c c}\right)$, (b) Equipment costs $(P E C)$, (c) Weight $\left(M_{c c}\right)$

\subsubsection{Multi-objective optimization}

The results of the multi-objective optimization consist of a three-axis Pareto front, in which each axis represents one of the established objectives. In order to simplify the result visualization, three graphs are created, see Fig. 7 In each graph two objectives are analyzed, for both single-pressure and doublepressure arrangements. Each point of the Pareto front represents a feasible solution of the presented calculation. Thus, it also represents a set of variables and a specific arrangement for the combined cycle. As some variables are integer by nature, the Pareto front of both arrangements presents results with similar layouts, these result groups are considered as clusters, they have similar decision variables and offer similar objective values. $\mathrm{CO}_{2}$ and fuel consumption reductions, for both single and double-pressure optimization cases, are expected to be between the extreme points of the singleobjective optimization values presented previously.

The single-pressure optimization results in three differentiated solution clusters. This distinction is most appreciable for the equipment costs objective. Higher, medium and lower cost clusters are visible in Fig. 7 (b). The clusters are characterized by the total quantity of gas turbines in the whole power plant, being 6,5 and 4, respectively for each cluster. As an overall trend, gas turbine efficiency increases, reducing the exhaust gas temperature. This characteristic produces a rise in heat transfer 
area, in order to obtain high overall combined cycle thermal efficiencies. This reflects in an increase of HRSGs size and cost along with downstream components. The gas turbine inlet temperature is in average $1506 \mathrm{~K}$ for all single pressure results. The three objectives show an overall positive correlation when considering all results, meaning that weight, cost and efficiency increase all together and vice versa. However, this trend is not visible among each cluster values, especially weight objective tends to be more disperse and less correlated with the other objectives. An overview of each cluster details is shown below.

Low cost solutions, seen in Fig. 7 (b) as a cluster around 90 MMUSD, are characterized by gas turbines with higher ratings and lower isentropic efficiencies; $\eta_{p t}=87.1-87.3 \%$ and $\eta_{c o}$ $=88.5-89.6 \%$. The power plant would be composed by four $35.52 \mathrm{MW}$ gas turbines, in combined cycle blocks of 1(1)x1 or 2(2)x1. For this cluster, the influence of pinch point and isotropic efficiencies on the overall thermal efficiency are more noticeable, as they have larger variation spans when compared with medium and higher costs clusters. The combination of low pinch points, varying $5 \mathrm{~K}$ along the cluster, and high isentropic efficiencies results in overall higher thermal efficiencies.

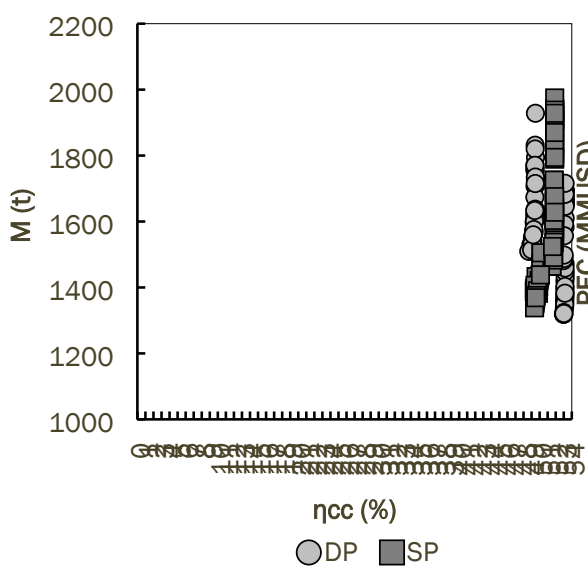

(a)

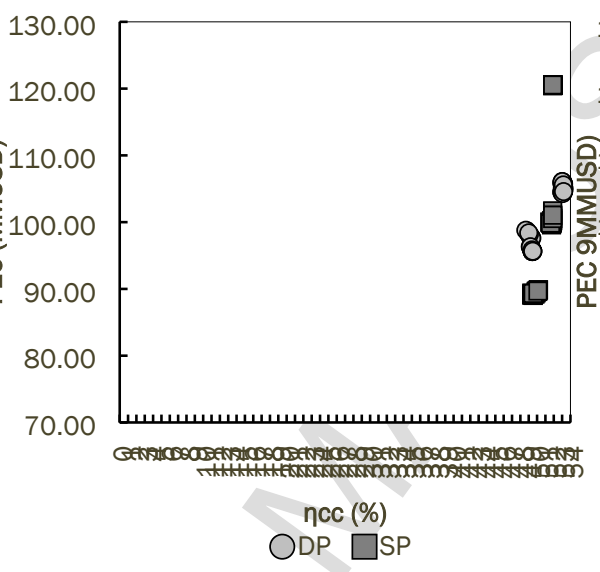

(b)

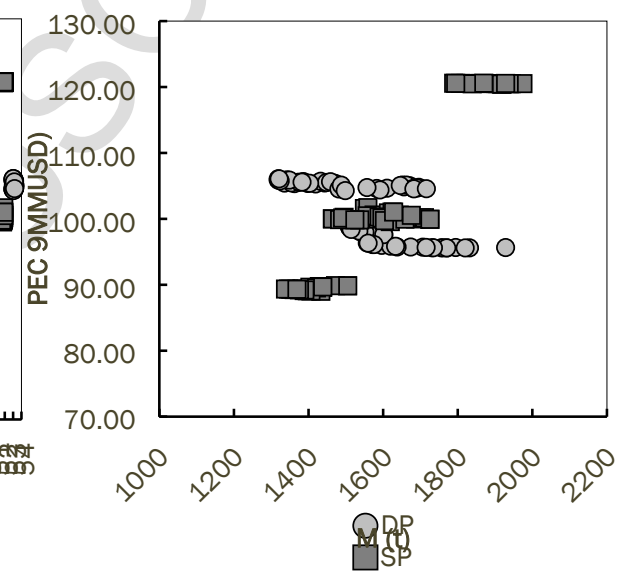

(c)

Fig. 7 Pareto fronts results of the multi-objective optimization study: a) Weight (M) vs. Efficiency $\left.\left(\eta_{c c}\right), b\right)$ Costs $(P E C)$ vs. Efficiency $\left.\left(\eta_{c c}\right), c\right)$ Costs (PEC) vs. Weight (M)

The results indicate that the medium cost level power plants have five blocks, with gas turbine ratings ranging 32.29 to $32.92 \mathrm{MW}$ in 1(1)x1 CC layouts. In addition to having an influence on the block arrangement, the power plant costs are influenced by small changes on the gas turbine rating. Larger ratings produce higher costs, and vice versa. The influence of the pinch point is similar as the one explained for the previous cluster with a narrower variation span $(2 \mathrm{~K})$. The mechanical efficiencies in the gas turbines present limited variations, thus having limited effects on the performances.

Finally, the results indicate that the three-block arrangements have the highest costs. In this cluster, combined cycle blocks are arranged in two gas turbines of $32.35 \mathrm{MW}$, i.e. 2(2)x1. Design parameters are more constant and their variation span is negligible, and thus their influence in result does not present a specific trend. Specifically, pinch point value averages $20 \mathrm{~K}$, and mechanical efficiencies in the gas turbine are at the upper bound, $\eta_{p t}=\eta_{c o}=90 \%$. The relation between gas turbine rating and overall costs is similar as described for the medium cost cluster.

The Pareto front for dual-pressure arrangement presents two main result clusters, namely, power plants featuring four and six gas turbines. Four gas turbine arrangements appear in a cluster surrounding efficiencies around 49\% in Fig. 7 (a). Six turbine arrangements are the cluster with average efficiency of 53\% in the same figure. In this case, the cluster results are highly differentiated, due to the large gap between average gas turbine ratings between the two clusters, being $34.26 \mathrm{MW}$ and 25.05 MW, respectively. The gas turbine inlet temperature also presents an approximate gap of $100 \mathrm{~K}$ between the clusters. Another differentiation feature is the presence of combined cycle blocks 
with a shared HRSG among the gas turbines, instead of a separate HRSG for each gas turbine. High HP pinch points and low LP pinch points are related to better thermal efficiencies in both clusters. Clusters details are presented as follows.

The first cluster of lower efficiencies is formed by two configurations containing four gas turbines, two CC blocks 2(2)x1 or one block 4(4)x1. In this cluster, objectives and variable trends are more correlated. As compressor isentropic efficiency decreases, so does the thermal efficiency and overall weight. On the contrary, it produces an increase in overall costs. An increase in steam cycle high pressure results in a weight reduction and in cost increase. Optimal gas turbine inlet temperature is about $1452 \mathrm{~K}$ with very small variation span. The results suggest that the cost increases when splitting four gas turbines into two blocks, due to the introduction of additional steam cycle components. This block distribution also affects the thermal efficiency, as in one CC block there are four HRSG, meaning a larger heat transfer area, thus increasing the thermal efficiency compared with the twoblock arrangement. Even though block distribution is discrete, cost and thermal efficiency variations are smooth among the results and they also depend on gas turbine properties.

The second cluster is characterized by power plants having six gas turbines in two blocks of three gas turbines each. The cluster is divided into power plants having two types of blocks, 3(3)x1 or 3(1)x1. This cluster presents the highest thermal efficiencies of all multi-objective optimized results, ranging from $53.0 \%$ to $53.2 \%$. The main difference between both clusters is the shared HRSG. This characteristic, along with fact that some design values are close to their bounds, make the relation among variables more disperse. Isentropic efficiencies in the gas turbine are in average $\eta_{p t}=\eta_{c o}$ $=89 \%$. The gas turbine inlet temperature varies between 1525 and $1537 \mathrm{~K}$. As the isentropic efficiencies remain constant, small changes in the LP pinch point (varying from 16.8 to $17.6 \mathrm{~K}$ ) affect the overall thermal efficiency $(52.9 \%$ to $53.2 \%)$. The HP pinch point remains almost constant around $26.8 \mathrm{~K}$ for all solutions. As detailed for the previous cluster, also in this case, the cost is influenced by the block layout and gas turbine properties.

\subsubsection{Multi-objective block layout}

This section explores and compares two possible solutions for each HRSG case. Multi-objective optimization results offered a wide range of layouts for combined cycle arrangements, Pareto fronts offered over 140 possible solutions divided into five clusters, two for double pressure HRSG (A and B) and three for single pressure HRSG (C, D and E). Table 4 shows a typical solution of each cluster, clusters A and B have diverse arrangements among them, thus, they are subdivided into two different solutions each. As any trade-off analysis, there must be some penalties when selecting more feasible arrangements. Considering the single pressure HRSG case, a knee solution could be located around cluster D, which have approximate average objective values when analyzing overall Pareto front range, in this case, an increase in efficiency would result in a high capital investment, which could have marginal benefits, raising $20 \%$ of capital cost would result in a $0,1 \%$ increase in efficiency. On the other side, poor efficiencies as in cluster $\mathrm{C}$, are undesired because of reduced economic and environmental benefits. 
Table 4. Representative solutions of Pareto front clusters

\begin{tabular}{lrrrrrrrrr}
\hline Case & $\begin{array}{r}\text { PEC } \\
\text { (MMUSD) }\end{array}$ & $\begin{array}{rrrrr}\text { WEIGT } \\
(\mathbf{t})\end{array}$ & $\begin{array}{r}\text { EFF } \\
(\%)\end{array}$ & Blocks & $\begin{array}{r}\text { GTs per } \\
\text { Block }\end{array}$ & $\begin{array}{r}\text { GT } \\
\text { Rating } \\
(\mathbf{M W})\end{array}$ & $\begin{array}{r}\text { HRSG } \\
\text { per } \\
\text { Block }\end{array}$ & $\begin{array}{r}\text { ST } \\
\text { Rating } \\
(\mathbf{M W})\end{array}$ & $\begin{array}{r}\text { Total } \\
\text { Capacity } \\
(\mathbf{M W})\end{array}$ \\
\hline DP (A1) & 98.00 & 1551 & 49.11 & 2 & 2 & 34.32 & 2 & 19.45 & 176.18 \\
DP (A2) & 95.61 & 1770 & 49.42 & 1 & 4 & 34.20 & 4 & 38.95 & 292.60 \\
\hline DP (B1) & 105.56 & 1376 & 53.15 & 2 & 3 & 25.06 & 1 & 17.78 & 168.17 \\
DP (B2) & 104.58 & 1716 & 53.17 & 2 & 3 & 24.98 & 3 & 17.72 & 203.04 \\
\hline SP (C) & 89.21 & 1390 & 49.75 & 2 & 2 & 35.53 & 2 & 17.02 & 176.16 \\
SP (D) & 100.11 & 1635 & 51.82 & 5 & 1 & 32.34 & 1 & 6.45 & 168.14 \\
SP (E) & 120.53 & 1902 & 51.88 & 3 & 2 & 32.36 & 2 & 13.00 & 220.17 \\
\hline
\end{tabular}

Double pressure HRSG Pareto front results in overall better performances, the analysis remains similar as carried out for single pressure arrangement: less efficient solutions are less likely to introduce benefits, in this sense, cluster B presents more promising solutions. Concerning weight results for this case, studies by Nord et al [8] show optimal weight-to-power ratios for offshore Rankine cycles in around $33.2 \mathrm{~kg} / \mathrm{kW}$ for a Northern Sea platform and contemplating additional 200 $\mathrm{t}$ of auxiliary steam cycle equipment, even though ambient temperatures may affect overall results, this value is taken as a comparing reference. Considering similar auxiliary weight, B1 and B2 cluster results in weight-to-power ratios of $34.5 \mathrm{~kg} / \mathrm{kW}$ and $40.1 \mathrm{~kg} / \mathrm{kW}$ respectively, therefore, B1 could be a representative solution for the double pressure HRSG Pareto front, because its overall low weight, high efficiency and medium costs. Lower weight-to-power ratio for this solution is due to the shared HRSG layout in B1. Evaluating a sensitivity of $10 \%$ on steam cycle auxiliary components weight, weight-to-power ratio extreme values would be between and 33.4 and $35.7 \mathrm{~kg} / \mathrm{kW}$, which is within the expected range.

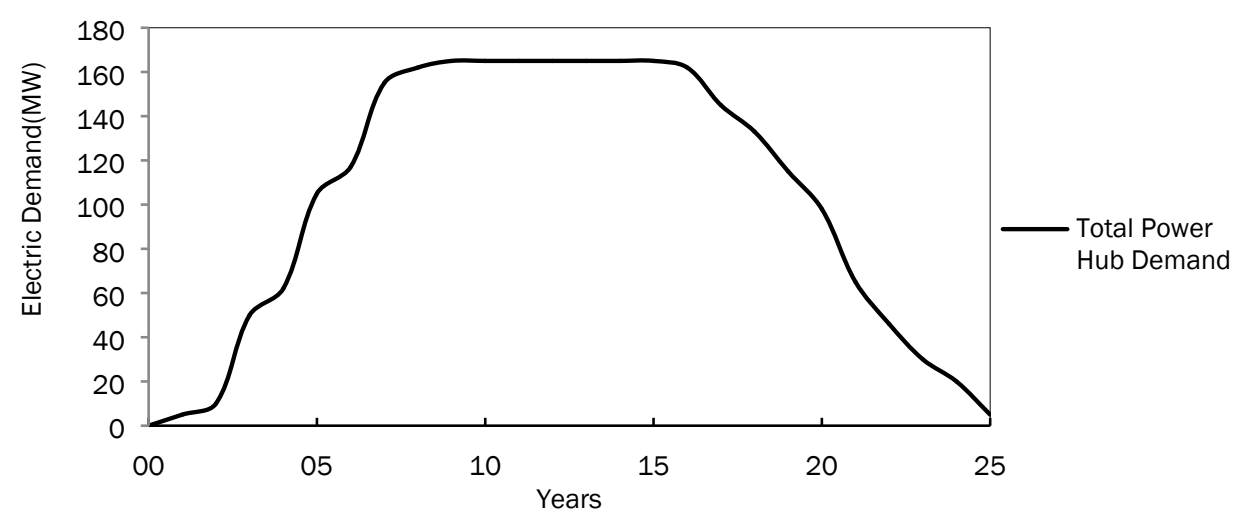

Fig. 8 Power Hub demand considering three FPSOs starting in years 0, 2 and 4

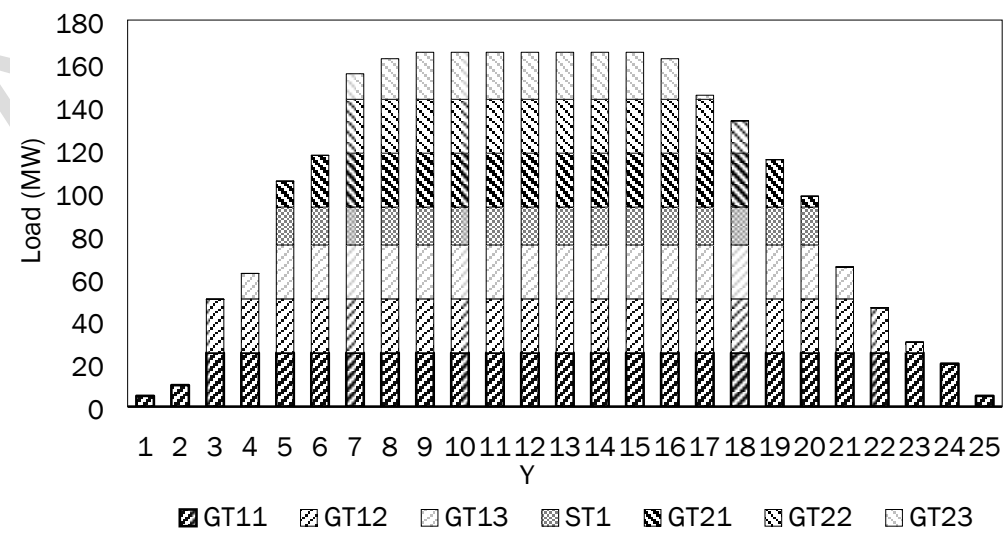


A more profound analysis of this solution needs a set of considerations and simplifications in order to obtain more realistic scenarios. Thermodynamic off-design calculations are out of the scope of this paper; however, this is a common situation expected during the power hub lifetime, which would be approximately 25 years. The proposed double pressure solution has two combined cycled blocks of three gas turbines each, an approximate curve load studied by Gallo et al [1] seen in Fig. 8 is the base to calculate the approximate dispatch in Fig. 9, this dispatch shows that part load would be more common on GTs than on CC itself.

Calculating fuel consumption for part-load periods is critical to obtain a rough estimation of surplus fuel gas. Fuel consumption curves tend to have similar characteristics and slopes among similar turbines, such as LM2500 model and gas turbine in B1 which have similar ratings, LM2500 fuel consumption and load increase linearly, as obtained in Thermoflex ${ }^{\circledR}$ [21], this linear behavior is adapted to gas turbine in B1 in order to calculate part-load fuel consumption. Approximate lifetime fuel consumption in a BAU case is $8.38 \mathrm{kt}$, applying a power hub arrangement, and considering the aforementioned artifices to calculate GTs fuel consumption, would result in $6.78 \mathrm{kt}$ (2.93 from cogeneration gas turbines and 3.85 from combined cycle blocks), that is $19 \%$ reduction with respect to the BAU case. Levelized gas opportunity costs highly depend on fuel prices, a price range between 3 to 4 USD/MMBTU would give a levelized benefit range of 104 to 134 MMUSD respectively (with a discount rate of $6 \%$ ). Surplus gas sells only would not cover all investment, since capital costs of 105 MMUSD increase approximately 2.7 times in installation, piping, control and commissioning costs [33], besides operation and maintenance.

\section{Conclusions}

This paper presented a method for identifying the optimal design of a gas and steam turbine combined cycle tailored for an off-shore power hub. Specifically, a design tailored to satisfy the Brazilian presalt basin specific needs was proposed. Both a single-objective and multi-objective optimization studies were carried out, incorporating the performance, weight and cost of the combined cycle. The proposed method allowed identifying a wide range of alternative combined cycle design solutions, including the design and quantity of gas turbines.

The results of the single-pressure optimization suggest that there are not clear benefits of choosing a single-pressure heat recovery steam generator. In order to reach the maximal thermal efficiency, larger heat transfer areas are required compared to dual-pressure arrangements, resulting in high costs and weight. The effects of introducing commercial gas turbines is clear; the highest combined cycle thermal efficiency was obtained with the high efficiency gas turbine (LM2500), while a lower combined cycle cost was obtained when using a lower cost-to-power ratio gas turbine (SGT-800-50). The results indicate that reducing compressor and gas turbine isentropic efficiencies have a large negative impact on combined cycle thermal efficiency, but a less pronounced effect on the plant weight and cost, since the also the size of the steam cycle is reduced due to drop in compressor and turbine performances.

The results of the multi-objective optimization indicate that dual-pressure arrangement steam cycles, featuring 3 gas turbines, 1 heat recovery steam generator and 1 steam cycle, could be an attractive design solution for power hubs. Because of the high efficiency and cost-benefit it presents when compared to other results. This arrangement has a low cost and weight, while the thermal efficiency is maintained at a reasonable high level (around $53.2 \%$ ). Moreover, the results indicate that by introducing a power hub, the $\mathrm{CO}_{2}$ emissions may be reduced by $18.7 \%$ to $27.2 \%$ when compared with a conventional floating production and storage unit at design point. A lifespan estimate for this solution confirms its potential to reduce fuel consumption and greenhouse gases emissions, in approximately 19\% compared to BAU lifetime emissions. However, it would still need further mechanisms to improve cost-effectiveness. Even though there is an increased energy demand 
because of the high quantity of gases coming from the well and the heating processes, the methodology aims to reduce part-load operations which is common in offshore oil industry.

Finally, it needs to be pointed out that it is of crucial importance to find out if a selected design will maintain an efficient operation while the heat and power demands are varying over time, by applying off-design thermodynamic calculations. Further work must consider to extend the methodology presented in this paper to include other operating conditions of the off-shore platforms, or other boundary conditions, such as other off-shore oil basins. Additionally, further income mechanisms such as exporting energy to shore should be explored to increase overall economic performance.

\section{Acknowledgments}

The authors acknowledge the Brazilian program for High-Education support (CAPES) for the economical funds, as well as the International Post-graduate Exchange program of Santander Bank. This paper is part of a Research and Development project supported by British Gas, part of Shell Group.

\section{Nomenclature}

$\begin{array}{ll}\text { PEC } & \text { Purchase Equipment Cost } \\ G T I & \text { Gas Turbine Index, } \mathrm{n} / \mathrm{d} \\ \text { NTR } & \text { Number of Turbines per Block, } \mathrm{n} / \mathrm{d} \\ H X I & \text { Heat Exchanger per Block, } \mathrm{n} / \mathrm{d} \\ H T A & \text { Heat Transfer Area }\left(\mathrm{m}^{2}\right) \\ W & \text { Power }(\mathrm{MW}) \\ M & \text { Weight }(\mathrm{t}) \\ M M U S D & \text { Million Dollars }\end{array}$

\section{Subscripts and superscripts}

$\begin{array}{ll}1 & \text { Inlet flow } \\ 2 & \text { Outlet flow } \\ \text { C } & \text { Compressor } \\ \text { CM } & \text { Combustor } \\ \text { COND } & \text { Condenser } \\ \text { CT } & \text { Compressor Turbine } \\ \text { EC } & \text { Economizer } \\ \text { EV } & \text { Evaporator } \\ \text { GT } & \text { Gas Turbine } \\ \text { HRSG } & \text { Heat Recovery Steam Generator } \\ \text { HP } & \text { High Pressure } \\ \text { LP } & \text { Low Pressure } \\ \text { PT } & \text { Power Turbine } \\ \text { SH } & \text { Super Heater } \\ \text { ST } & \text { Steam Turbine }\end{array}$

\section{References}

[1] Gallo WLR, Gallego AG, Acevedo VL, Dias R, Ortiz HY, Valente BA. Journal of Natural Gas Science and Engineering Exergy analysis of the compression systems and its prime movers for 
a FPSO unit. J Nat Gas Sci Eng 2017;44:287-98. doi:10.1016/j.jngse.2017.04.023.

[2] De Oliveira S, Van Hombeeck M. Exergy analysis of petroleum separation processes in offshore platforms. Energy Convers Manag 1997;38:1577-84. doi:10.1016/S01968904(96)00219-1.

[3] Carranza Sánchez YA, de Oliveira S. Exergy analysis of offshore primary petroleum processing plant with CO2 capture. Energy 2015;88:46-56. doi:10.1016/j.energy.2015.05.130.

[4] Barrera JE, Bazzo E, Kami E. Exergy analysis and energy improvement of a Brazilian floating oil platform using Organic Rankine Cycles. Energy 2015;88:67-79. doi:10.1016/j.energy.2015.03.091.

[5] Reis MML, Gallo WLR. Study of waste heat recovery potential and optimization of the power production by an organic Rankine cycle in an FPSO unit. Energy Convers Manag 2018;157:409-22. doi:10.1016/j.enconman.2017.12.015.

[6] Pierobon L, Nguyen T Van, Larsen U, Haglind F, Elmegaard B. Multi-objective optimization of organic Rankine cycles for waste heat recovery: Application in an offshore platform. Energy 2013;58:538-49. doi:10.1016/j.energy.2013.05.039.

[7] Nguyen T-V, Tock L, Breuhaus P, Maréchal F, Elmegaard B. Oil and gas platforms with steam bottoming cycles: System integration and thermoenvironomic evaluation. Appl Energy 2014;131:222-37. doi:10.1016/j.apenergy.2014.06.034.

[8] Nord LO, Martelli E, Bolland O. Weight and power optimization of steam bottoming cycle for offshore oil and gas installations. Energy 2014;76:891-8. doi:10.1016/j.energy.2014.08.090.

[9] Orlandini V, Pierobon L, Schløer S, De Pascale A, Haglind F. Dynamic performance of a novel offshore power system integrated with a wind farm. Energy 2016;109:236-47. doi:10.1016/j.energy.2016.04.073.

[10] Hetland J, Kvamsdal HM, Haugen G, Major F, Kårstad V, Tjellander G. Integrating a full carbon capture scheme onto a 450 MWe NGCC electric power generation hub for offshore operations: Presenting the Sevan GTW concept. Appl Energy 2009;86:2298-307. doi:10.1016/j.apenergy.2009.03.019.

[11] Manassaldi JI, Mussati SF, Scenna NJ. Optimal synthesis and design of Heat Recovery Steam Generation (HRSG) via mathematical programming. Energy 2011;36:475-85. doi:10.1016/j.energy.2010.10.017.

[12] Manassaldi JI, Arias AM, Scenna NJ, Mussati MC, Mussati SF. A discrete and continuous mathematical model for the optimal synthesis and design of dual pressure heat recovery steam generators coupled to two steam turbines. Energy 2016;103:807-23. doi:10.1016/j.energy.2016.02.129.

[13] Rovira A, Sánchez C, Muñoz M, Valdés M, Durán MD. Thermoeconomic optimisation of heat recovery steam generators of combined cycle gas turbine power plants considering off-design operation. Energy Convers Manag 2011;52:1840-9. doi:10.1016/j.enconman.2010.11.016.

[14] Mehrgoo M, Amidpour M. Constructal design and optimization of a dual pressure heat recovery steam generator. Energy 2017;124:87-99. doi:10.1016/j.energy.2017.02.046.

[15] Windén B, Chen M, Okamoto N, Kim DK, McCaig E, Shenoi A, et al. Investigation of offshore thermal power plant with carbon capture as an alternative to carbon dioxide transport. Ocean Eng 2014;76:152-62. doi:10.1016/j.oceaneng.2013.07.016.

[16] Kaviri AG, Jaafar MNM, Lazim TM. Modeling and multi-objective exergy based optimization of a combined cycle power plant using a genetic algorithm. Energy Convers Manag 2012;58:94-103. doi:10.1016/j.enconman.2012.01.002.

[17] Riboldi L, Nord LO. Concepts for lifetime efficient supply of power and heat to offshore installations in the North Sea. Energy Convers Manag 2017;148:860-75. doi:10.1016/j.enconman.2017.06.048.

[18] Barbosa YM, Julio AM, Junior SDO, Torres EA. Performance assessment of primary 
petroleum production cogeneration plants. Energy 2018;160:233-44. doi:10.1016/j.energy.2018.07.014.

[19] Toffolo A, Lazzaretto A. Evolutionary algorithms for multi-objective energetic and economic optimization in thermal system design. Energy 2002;27:549-67. doi:10.1016/S03605442(02)00009-9.

[20] The MathWorks Inc. MATLAB n.d.

[21] Thermoflow. Thermoflex 2017.

[22] Saravanamuttoo H, Rogers G, Cohen H, Straznicky P. Gas turbine theory. 6th ed. Dorset, UK: PEARSON Prentice Hall; 2009.

[23] Rivera-Alvarez A, Coleman MJ, Ordonez JC. Ship weight reduction and efficiency enhancement through combined power cycles. Energy 2015;93:521-33. doi:10.1016/j.energy.2015.08.079.

[24] Dumont M-N, Heyen G. Mathematical modelling and design of an advanced once-through heat recovery steam generator. Comput Chem Eng 2004;28:651-60. doi:10.1016/j.compchemeng.2004.02.034.

[25] Gnielinski V. On heat transfer in tubes. Int J Heat Mass Transf 2013;63:134-40. doi:10.1016/j.ijheatmasstransfer.2013.04.015.

[26] ESCOA. Fin Tube Technology. 1st ed. Oklahoma: 1979.

[27] Haug KC. Weight Estimation of Steam Cycle for CO2 Capture System on Offshore Oil and Gas Installation. NTNU, 2016.

[28] Gas Turbine World. Performance Specs 2016;46.

[29] Frangopoulos CA. Comparison of thermoeconomic and thermodynamic optimal design of a combined-cycle plant. In: Kouremenos DA, editor. Proc. Int. Conf. Anal. Therm. Energy Syst., Athens: 1991.

[30] Carapellucci R, Giordano L. A comparison between exergetic and economic criteria for optimizing the heat recovery steam generators of gas-steam power plants. Energy 2013;58:458-72. doi:10.1016/j.energy.2013.05.003.

[31] Roosen P, Uhlenbruck S, Lucas K. Pareto optimization of a combined cycle power system as a decision support tool for trading off investment vs. operating costs. Int $\mathrm{J}$ Therm Sci 2003;42:553-60. doi:10.1016/S1290-0729(03)00021-8.

[32] Shah R, Sekulić D. Fundamentals of Heat Exchanger Design. Hoboken, New Jersey: Wiley; 2003.

[33] Bejan A, Tsatsaronis G, Moran M. Thermal Design and Optimization. Hoboken: John Wiley \& Sons; 1995. 


\section{Highlights}

- A power hub design was optimized to improve energy efficiency in oil platforms

- Gas turbine design was integrated to comprehend more component selection scenarios

- Single-pressure and double-pressure heat recovery steam generators were considered

- All power hub scenarios resulted in lower fuel consumption and $\mathrm{CO} 2$ emissions 